\title{
A Dilemma for Benatar's Asymmetry Argument
}

\author{
Fumitake Yoshizawa ${ }^{1}$
}

Accepted: 8 April 2021/ Published online: 13 May 2021

(C) The Author(s) 2021

\begin{abstract}
In this paper, I show that David Benatar's asymmetry argument for anti-natalism leads to a dilemma. In Chapter 2 of his book Better Never to Have Been, Benatar claims that there is an axiological asymmetry between harms and benefits that explains four prevalent asymmetries. Based on the axiological asymmetry, he defends the anti-natalist conclusion that we should not have children. The four prevalent asymmetries to be explained are moral duties, reasons, attitudes, or feelings concerning life as a whole. However, Benatar explains them by applying the axiological asymmetry to parts of life, such as pains and pleasures. I find a serious gap here. While two ways are available to bridge this gap, a dilemma arises from Benatar's asymmetry argument. The axiological asymmetry is not supported because it cannot explain the four prevalent asymmetries, or else it cannot lead to the anti-natalist conclusion. A number of philosophers have already criticized Benatar's asymmetry argument, mainly questioning its assumptions. In this paper, I contend that there is no good reason to agree with his argument even if all its explicit assumptions are accepted.
\end{abstract}

Keywords David Benatar · Procreational duties · Asymmetry argument $\cdot$ Anti-natalism $\cdot$ Life as a whole

\section{Introduction}

In his much-discussed book Better Never to Have Been, David Benatar (2006) argues that there is an axiological asymmetry between harms and benefits: while the presence of harm is bad and the absence of harm is good, the presence of benefit is good, but the absence of benefit is not bad unless there exists someone for whom it is a deprivation. A person's life may encompass many benefits, but because their absence is not bad, the presence of benefit never gives a life any advantage over nonexistence. In contrast, because the presence of harm is

Fumitake Yoshizawa

fumitake.yoshizawa@gmail.com

1 Global Center for Higher Education, Akita University, 1-1 Tegata Gakuen-machi, Akita 010-8502, Japan 
disadvantageous over its absence, it gives a life a disadvantage over nonexistence. Hence, Benatar concludes that coming into existence is always a harm. Based on this evaluation, he derives the anti-natalist conclusion that we should not have children. Benatar's main argument for his axiological asymmetry that leads to such a conclusion invokes its power to explain four prevalent asymmetries, including our asymmetrical duties of procreation, according to which we have a duty to avoid bringing a miserable life into existence but do not have a duty to bring a happy life into existence.

In this paper, I show that there is a non-negligible gap in Benatar's asymmetry argument. The four prevalent asymmetries to be explained concern life as a whole. However, the axiological asymmetry is applied to parts of life, such as pain and pleasure. Benatar does not explain how the evaluations of parts of life are relevant to the evaluations of life as a whole. There are two options available to bridge the gap; however, based on these, a dilemma arises from the asymmetry argument. One option is to apply, as Benatar does, the axiological asymmetry to parts of life, which leads to the anti-natalist conclusion. However, the axiological asymmetry is not supported if it is applied in this way because it cannot explain the prevalent asymmetries pertaining to life as a whole. The other option is to apply the axiological asymmetry to life as a whole. That would be supported by its explanatory power, but it would no longer lead to the anti-natalist conclusion because the asymmetry would lead to that conclusion only if it was applied to parts of life.

In this paper, I initially present Benatar's asymmetry argument. Next, I detail the serious gap that exists in his argument. Then, I show that his argument leads to the dilemma described above. In doing so, I claim that there is no good reason to agree with Benatar's asymmetry argument even if we accept all his basic assumptions. To be fair to Benatar, I provide a detailed reconstruction of his argument in the next section, although it is already well known. The novel critique that I present ${ }^{1}$ cuts to the heart of the structure of Benatar's asymmetry argument.

\section{Benatar's Asymmetry Argument}

As the basis of the argument, Benatar asserts the following "axiological asymmetry" between harms and benefits (Benatar and Wasserman 2015, 23) ${ }^{2}$ :

1. The presence of harm is bad; and

2. the presence of benefit is good.

3. The absence of harm is good, even if that good is not enjoyed by anyone; but

4. the absence of benefit is not bad unless there is somebody for whom this absence is a deprivation.

Benatar $(2006,30 ; 2013,122)$ thinks that pains and pleasures are exemplars of harms and benefits and that the asymmetry also holds between other kinds of harms and benefits - for

\footnotetext{
${ }^{1}$ Benatar (2012, 2013) has responded comprehensively to his book's critics. More recently, Benatar (2019) also responded to critiques by Christine Overall (2012, Chapter 6).

2 See also Benatar 2006, 30. The term "axiological asymmetry" is from Benatar and Wasserman 2015, 21. This asymmetry is also called "basic asymmetry" elsewhere; see Benatar 2013, 123.
} 
example, between desire frustrations and desire satisfactions. This is an important point, to which I will return later.

Figure 1 shows the application of the axiological asymmetry to the comparison between a situation in which a person comes into existence and a situation in which that person never comes into existence (Benatar and Wasserman 2015, 23, Fig. 2.1).

Benatar calls attention to the accurate reading of this figure: compare (1) with (3) and (2) with (4), not (1) with (2) or (3) with (4). In Benatar's words:

To decide the relative advantages and disadvantages of coming into existence and of never coming into existence, we need to compare (1) with (3), and (2) with (4). When we make the first comparison we find that never existing is preferable to coming into existence. The absence of harm in Scenario B is an advantage over the presence of harm in Scenario A. However, when we compare (2) with (4) we see that the presence of benefit in Scenario A, although good for X, is not an advantage over the absence of benefit in Scenario B. (Benatar and Wasserman 2015, 24)

Additionally, Benatar $(2006,43)$ writes that "(2) is not an advantage over (4), whereas (1) is a disadvantage relative to (3)" (emphasis added). ${ }^{3}$ While the pairing of the "good" of (3) and the "bad" of (1) plausibly renders "good" advantageous over "bad," it is not clear why the "good" of (2) is not advantageous over the "not bad" of (4). Moreover, Benatar does not clearly state how (4) may be comparatively evaluated against (2). It seems natural to read him as claiming that (4) is "not a disadvantage" over (2) since he claims elsewhere (2006, 42 ) that (4) is "not worse" than (2). However, I presuppose only what Benatar clearly states. The point here is that it is clear from the term "preferable" that he makes a comparative evaluation of the scenarios. ${ }^{4}$

Some philosophers have cast doubt on an assumption of the above evaluation, namely, that nonexistence can have value for a person who never exists in that situation. For example, according to Elizabeth Harman (2009, 780-781), while the evaluations of (1) and (2) concern personal badness and goodness, (3) and (4) should be impersonal evaluations that do not refer to a particular person. Accordingly, comparisons between (1) and (3) and between (2) and (4) cannot be made. In response, Benatar explains how to make sense of the idea according to which (3) and (4) are both personal evaluations: they can be made "with reference to the interests of the person who exists in one (and only one) of these two possible worlds" (2013, 125). At any rate, I simply accept his view: (1) through (4) are all personal evaluations. While I am inclined to agree with Benatar's view on this point, my main reason for accepting it is that, as stated earlier, I seek to criticize his asymmetry argument while accepting all his basic assumptions.

\footnotetext{
${ }^{3}$ Benatar $(2006,42-43)$ makes this statement not when he directly explains how we should read Fig. 1 but when he illustrates (but does not prove) how the axiological asymmetry works to make asymmetrical comparative evaluations using the analogy of hypothetical persons named "S (Sick)" and "H (Healthy)."

"It would appear simpler to use "better" or "worse" to express the comparative evaluations of the scenarios, as Benatar also writes that "the pleasures in A [(2)] are not better than the absent pleasures in B [(4)]" $(2006,41)$ and "[i]t [(3)] claims that it is better than the presence of pain [(1)]" $(2013,128)$. However, I use the expression "(dis)advantage" because it permits a more flexible usage befitting of Benatar's purpose. The concepts of betterness and worseness are generally known as having strict formal features. As Ben Bradley (2010, 2-3) rightly indicates, it is formally incoherent to claim that the "good" in (2) is not better than the "not bad" in (4).
} 


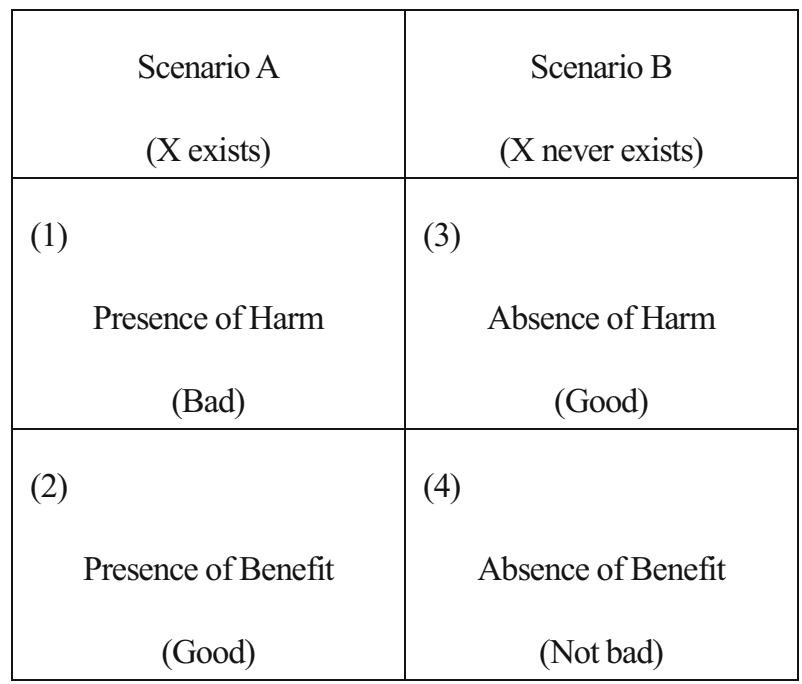

Fig. 1 Asymmetry between harms and benefits

Let us now see how Benatar's claim that coming into existence is always a harm results from the evaluations presented in Fig. 1. When Scenario A is chosen, X comes into existence, and X's life then encompasses harms and benefits, such as pains and pleasures. A harm in Scenario A is evaluated as "bad," and a benefit is evaluated as "good." These are noncomparative evaluations, in contrast to comparative evaluations between scenarios. ${ }^{5}$ In comparison with Scenario B, each harm (1) in Scenario A is evaluated as disadvantageous over the absence of harm (3), while each benefit (2) is not evaluated as advantageous over the absence of benefit (4). Based on these comparative evaluations of parts of life (or components of life), such as pains and pleasures, Benatar examines whether Scenario A has comparative advantages over Scenario B as a whole. This is a whole-life evaluation in the sense that it specifies how the assessments of the parts of life contribute to the assessments of the whole life. ${ }^{6}$ No matter how many pleasurable "parts" are present in Scenario A, these parts never give Scenario A an advantage over Scenario B. However, just one pain does give Scenario A a disadvantage over Scenario B. Even the best life with no harmful parts has neither an advantage nor a disadvantage over the absence of life. Moreover, such a life is never realized in the actual world. Therefore, Benatar $(2006,28-29,48-49,60)$ concludes that coming into existence is

\footnotetext{
5 This distinction between "non-comparative" and "comparative" is slightly different from Benatar's (2006, 41; 2012, 144-145) distinction between "intrinsic" and "relative." According to Benatar, (1) is intrinsically bad and relatively bad; (2) is intrinsically good (he does not make a statement on the relative value of (2) there); (3) is intrinsically neutral and relatively good; and (4) is intrinsically neutral and relatively not bad. In particular, (3) and (4) are, according to Benatar, intrinsically neutral. However, I ignore this distinction because I mention "noncomparative" value only when the evaluations of (1) and (2) are at issue. According to Benatar, regarding (1) and (2), there is no difference between the intrinsic and relative evaluations. Additionally, I use the concept of "(dis)advantage" explicitly employed by Benatar (2006, 40-42) for comparisons between scenarios when I mention "comparative" values.

${ }^{6}$ Benatar makes a whole-life evaluation when he states, "Scenario B has an advantage over Scenario A, but Scenario A has no advantage over Scenario B. We see then that the axiological asymmetry leads to the conclusion that coming into existence is always a net harm" (Benatar and Wasserman 2015, 24; emphasis added). This assertion is based on the evaluation of how each part of life is (dis)advantageous over its absence. This evaluation is not like a mere sum of all the numbers assigned to the component unit of life. However, it $i s$ a whole-life evaluation.
} 
not necessarily, but is in reality always, a harm, in the sense that it has disadvantages over never coming into existence. I call this mid-conclusion of his argument the "harmful birth conclusion." 7

Next, let us see how Benatar supports the axiological asymmetry that leads to this conclusion. He argues that the main support for the axiological asymmetry is that it best explains four prevalent asymmetries (Benatar 2006, 31-36; 2013, 123; Benatar and Wasserman 2015, 25-27). In other words, Benatar claims that the axiological asymmetry has explanatory power as a hypothesis for the best explanation of widely accepted beliefs. The first one is as follows:

(i). The asymmetry of procreational duties: "While we have a duty to avoid bringing into existence people who would lead miserable lives, we have no duty to bring into existence those who would lead happy lives" (Benatar 2013, 123).

Benatar explains this as follows:

$[\mathrm{T}]$ he reason why we think that there is a duty not to bring suffering people into existence is that the presence of this suffering would be bad (for the sufferers) and the absence of the suffering is good (even though there is nobody to enjoy the absence of suffering). In contrast to this, we think that there is no duty to bring happy people into existence because while their pleasure would be good for them, its absence would not be bad for them (given that there would be nobody who would be deprived of it). (Benatar 2006, 32)

In this explanation, the axiological asymmetry is used as the basis for the duties in question. Let us recall Fig. 1; putting aside other considerations, such as the happiness of parents, it would be straightforward to think that the negative axiological evaluation - "bad" — of (1) is connected to the negative moral duty - the "duty not to bring people into existence." However, the positive axiological evaluation - "good"- of (2) is not connected to the positive moral duty - the "duty to bring people into existence." This is because, according to Benatar, the absence of benefit (4) is "not bad" rather than "bad"; if the absence of benefit (4) is "bad," the positive axiological evaluation - "good" - of (2) would be connected to the positive moral duty - the "duty to do." Here, the evaluation - "not bad" — of (4) is intended to avoid the conclusion that there is a positive duty to create happy people. This reasoning is not entirely clear, as it is not clear why the "good" of (2) is not advantageous over the "not bad" of (4). If (2) is "good" and (4) is "not bad," there may still be a positive duty (or moral reason) to procreate, even if it is weak. At any rate, again, I simply accept Benatar's view; the presence of benefit with the "good" of (2) cannot be the basis of positive moral duties, reasons, attitudes, or feelings if its absence (4) is "not bad."

\footnotetext{
${ }^{7}$ This mid-conclusion is still an axiological claim; it is not yet the moral anti-natalist conclusion (Benatar and Wasserman 2015, 38 n. 6).

${ }^{8}$ As Benatar writes, it may be proposed that the general asymmetry of duties - "we have negative duties to avoid harm but no corresponding positive duties to bring about happiness" (2006, 32) - explains the asymmetry of procreational duties (see also footnote 9 in this paper). Benatar $(2006,32-34$; 2013, 127) laconically rejects this explanation of our procreational duties, however. I do not examine whether it can be an alternative to Benatar's because I would like to keep to his line of thought as much as possible. I return to this general asymmetry of duties in Section 5.1.
} 
In addition to (i), according to Benatar the following three asymmetries are also explained by the axiological asymmetry:

(ii). The prospective beneficence asymmetry: "It is strange to cite as a reason for having a child that that child will thereby be benefited. It is not similarly strange to cite as a reason for not having a child that that child will suffer" (Benatar 2013, 123).

(iii). The retrospective beneficence asymmetry: "When one has brought a suffering child into existence, it makes sense to regret having brought that child into existence-and to regret it for the sake of that child. By contrast, when one fails to bring a happy child into existence, one cannot regret that failure for the sake of the person" (ibid.).

(iv). The asymmetry of distant suffering and absent happy people: "We are rightly sad for distant people who suffer. By contrast we need not shed any tears for absent happy people on uninhabited planets, or uninhabited islands or other regions on our own planet" (ibid.).

Similar to the explanation in (i), Benatar's explanations for the other three would be as follows: A benefit with "good," as in (2), does not provide a positive reason to procreate because its absence (4) is "not bad" rather than "bad" (the first half of (ii)). The absence of benefit- "not bad" of (4) - does not make regret - a kind of negative attitude - for failing to create happy people appropriate (the second half of (iii)) and does not make sadness - a kind of negative feeling - for the unborn happy people appropriate (the second half of (iv)). In contrast, a harm with the negative evaluation of "bad," as in (1), provides a negative reason not to create people (the second half of (ii)). It also makes regret for the sake of the people who are brought into existence appropriate (the first half of (iii)) and sadness for distant people who suffer appropriate (the first half of (iv)).

In summary, according to Benatar, the axiological asymmetry is supported by the explanatory power of four asymmetries and results in the mid-conclusion that coming into existence is always a harm. Based on this, Benatar derives the anti-natalist conclusion. ${ }^{9}$ This is the framework of the asymmetry argument.

\section{Gap in Benatar's Argument}

Many critics of Benatar's asymmetry argument question its assumptions. To mention but a few examples, some claim that (all or some of) the four asymmetries are explained by principles other than the axiological asymmetry (Harman 2009, 781; Bayne 2010, 50-52; Metz 2011, 241-243), and some claim that the asymmetry of procreational duties is problematic (Bradley

\footnotetext{
${ }^{9}$ The connection between the harmful birth conclusion and the anti-natalist conclusion is not direct. According to Benatar, a minor harm may be outweighed by other considerations, such as the interests of others (Benatar and Wasserman 2015, 38 n. 6; see also Benatar 2006, 49). Moreover, Benatar does not assume any particular moral theories, especially utilitarianism $(2013,122 \mathrm{n}$. 6). Therefore, it is not appropriate to emphasize that "there has to be a moral 'bridge' premise" (Metz 2011, 237). Rather, it is better to think that Benatar's argument depends only on a primitive correspondence between axiological and moral assessments, for example, between the negative axiological evaluation — birth is harmful — and the negative moral (pro tanto) prescription — we should not have children. See also footnote 8 in this paper.
} 
2013) and that comparative evaluations based on the axiological asymmetry are incoherent (Bradley 2010). By contrast, I argue that the anti-natalist conclusion fails even if we accept all the explicit assumptions of Benatar's argument. I will present the gap in Benatar's argument, and based on it, the dilemma that arises from the asymmetry argument.

\subsection{The Gap}

Let us once more consider Benatar's explanation of (i):

[T]he reason why we think that there is a duty not to bring suffering people into existence is that the presence of this suffering would be bad (for the sufferers) and the absence of the suffering is good (even though there is nobody to enjoy the absence of suffering). In contrast to this, we think that there is no duty to bring happy people into existence because while their pleasure would be good for them, its absence would not be bad for them (given that there would be nobody who would be deprived of it). (Benatar 2006, 32; emphasis added)

Look at the two pairs of expressions emphasized in this passage: one is the pair "suffering would be bad" and "pleasure would be good"; the other is "a duty not to bring suffering people into existence" and "no duty to bring happy people into existence." The former pair is axiological evaluations of parts of life. However, the latter pair is moral duties concerning life as a whole. How the evaluation of parts of life is relevant to the evaluation of life as a whole is not stated here, although the lives of suffering and happy people may encompass both painful and pleasurable parts. The same can be said of the other three asymmetries. While all of them concern life as a whole, the axiological asymmetry that is alleged to explain them is applied to parts of life, such as pains and pleasures. Recall the three pairs of expressions, that is, (ii) "that child will thereby be benefited" and "that child will suffer," (iii) "suffering child" and "happy child," and (iv) "distant people who suffer" and "happy people." The point is that in the process of Benatar's explanation of the four asymmetries, the axiological asymmetry indicates how to evaluate parts of life. However, he does not explain how to evaluate life as a whole. This is the gap I find in his argument.

To bridge the gap, it is necessary to obtain an evaluation of life as a whole from the evaluations of parts of life. This as-a-whole evaluation can be obtained in two ways. First, we can make a comparative evaluation of parts of life based on the axiological asymmetry and subsequently evaluate life as a whole. Benatar originally derives his harmful birth conclusion in this manner. Second, we can make a non-comparative evaluation of life as a whole and subsequently conduct a comparative evaluation of the scenarios based on the axiological asymmetry. I detail below that the difference between these two ways of evaluation lies in the order of the steps taken for the evaluations: the former is "asymmetrical comparison first and as-a-whole evaluation second," and the latter is "as-a-whole evaluation first and asymmetrical comparison second." I demonstrate that while these two ways are available to bridge the gap, they present a dilemma for Benatar's asymmetry argument.

\subsection{First Horn: Asymmetrical Comparison First}

The first way to make an evaluation of life as a whole is using the harmful birth conclusion that all life as a whole is comparatively harmful; according to Benatar, regardless of whether a life 
is miserable or happy - that is, no matter how many harms or benefits it contains - only harmful parts that are comparatively disadvantageous over their absence are considered in the evaluation of life as a whole. This result is obtained using the axiological asymmetry with the order of "asymmetrical comparison first and as-a-whole evaluation second." Accordingly, the duties that are explained are as follows:

We have a duty to avoid bringing into existence people who would lead miserable lives because they are comparatively harmful, and we also have a duty to avoid bringing into existence those who would lead happy lives because they are comparatively harmful.

This is not the broadly accepted asymmetry of procreational duties, according to which we simply have no duty to bring happy lives into existence. Rather, this is nothing other than the anti-natalist conclusion. This result is not surprising because if the harmful birth conclusion is correct, the moral evaluations based on it should be anti-natalist, as Benatar claims.

Let us see how the explanations of other asymmetries would go. (ii) The prospective beneficence asymmetry would be as follows: The second half is explained; it is natural - it is not strange - to cite as a reason for not having a child the fact that the child will thereby suffer because she will also be comparatively harmed. However, the first half is not explained; it is certainly strange to cite as a reason for having a child the fact that the child will thereby be benefitted, but it is rather natural - it is not strange - to cite the fact as a reason for not having a child because she will be comparatively harmed. ${ }^{10}$ In other words, because all life is comparatively harmful regardless of whether it is noncomparatively harmful or beneficial, it always provides a reason not to procreate. This is clearly not the widely shared understanding of (ii).

Next, (iii) the retrospective beneficence asymmetry would be as follows: when one has brought a suffering child into existence, it makes sense to regret having brought that child into existence and to regret it for the sake of that child because she is comparatively harmed; by contrast, when one fails to bring a happy child into existence, one cannot regret that failure for the sake of the person but rather should feel at ease about that failure because she would be comparatively harmed. This is clearly not our commonsensical attitude.

Finally, (iv) the asymmetry of distant suffering and absent happy people would be as follows: we are rightly sad for distant people who suffer because they are comparatively harmed; by contrast, we need not shed any tears for absent happy people on uninhabited planets or uninhabited islands or other regions on our own planet, but rather we may feel pleased at their absence because they would be comparatively harmed. This is clearly not common sense. Taken together, if Benatar takes the

\footnotetext{
${ }^{10}$ It seems clear that our ordinary thought about procreation implies that it is strange to cite as a reason for not having a child the fact that the child will be non-comparatively benefitted; the alleged explanation of the first half of (ii) is incompatible with this. Here, I do not exclude the possibility as a theoretical conclusion that it is not strange - it is natural - to cite as a reason for not having a child the fact that the child will thereby be benefited (because she will be comparatively harmed). Such an anti-natalist conclusion can be plausible only when the axiological asymmetry applied to parts of life is supported based on its explanatory power. We should make a clear distinction between what is the observed data-(ii) the prospective beneficence asymmetry- to be explained, what is a hypothesis - the axiological asymmetry applied to parts of life - that is claimed to explain the data, and what is the theoretical conclusion - the anti-natalist conclusion at issue — of the hypothesis that most successfully explains the data. If I exclude the possibility in the entire argument, I cannot escape being criticized for begging the question. However, in explaining the broadly accepted four asymmetries, it is safe (or rather necessary) to assume as our commonsensical understanding that it is strange to cite as a reason not for having a child that the child will thereby be benefited.
} 
first route to bridge the gap, the axiological asymmetry is not supported because it fails to explain any of the other four asymmetries. This is the first horn of the dilemma.

\subsection{Second Horn: As-a-Whole Evaluation First}

In contrast, the second way to evaluate life as a whole is by first making a non-comparative evaluation of it. The asymmetrical comparisons are conducted afterward.

Several standards may work for obtaining an evaluation of a whole life. The simplest way is to think that the value is determined by the sum of the values of the beneficial and harmful parts of life; however, Benatar $(2006,45)$ opposes a simple calculation of this kind. ${ }^{11}$ In fact, reflecting on the nature of the explanation of our common sense, no strict method of calculation seems necessary. Moreover, even assigning numbers to the values of each whole life is not necessary. To understand this point, let us consider the question, "How do most people think about the morality of bringing a miserable and a happy life into existence?" A commonsense answer is, "We have a moral duty to avoid bringing a miserable life into existence, and we have no duty to bring happy people into existence." This answer is the asymmetry of procreational duties. Moreover, the question that the axiological asymmetry is supposed to answer is, "Why do we so think of our duties about bringing miserable and happy lives into existence?" In considering these questions, the point is to ensure that we are not required to explain the conceptions of a miserable and a happy life themselves in the answers. Additionally, we can easily have a conception of how well or ill a whole life goes even if it is a rough one. This is part of the reason that most of us feel surprised to hear that our life is always (comparatively) harmful-or non-comparatively worse (based on the quality-of-life argument in Benatar 2006, Chapter 3) - than we thought. ${ }^{12}$

At any rate, our ordinary conception of our lives is that there are both miserable and happy lives. Based on this, the explanation of (i) by virtue of the axiological asymmetry would be as follows: First, recall that the axiological asymmetry is proposed not just as the asymmetry between pains and pleasures but also as the general asymmetry of values for a person that can be applied to other kinds of harms and benefits. It can be applied to life as a whole. Indeed, in his response to David Spurrett's criticism, Benatar (2012, 131-132) admits that a valueless and a valuable life are also examples of harms and benefits, respectively. ${ }^{13}$ Figure 2 shows the results of replacing "harm" in Fig. 1 with "miserable life" and "benefit" with "happy life."

When Scenario A is chosen, person X comes into existence, and X's life will encompass both harmful and beneficial parts. Based on these parts of life, we could identify X's life as

\footnotetext{
${ }^{11}$ Benatar (2006, 61-64) rejects such a simple view of a whole-life evaluation when mentioning the asymmetry argument in Chapter 3 of his book. It should be emphasized that the non-comparative evaluation of whole life discussed here is different from what Benatar (2006, 44-49) criticizes in his asymmetry argument. What he finds fault with is the whole-life evaluation made by combining (1) with (2) and (3) with (4) in the scenarios in Fig. 1. Benatar explicitly writes, "Figure 2.1 [Fig. 1 in this paper] is not meant to be a guide to determining how bad it is to come into existence" $(2006,48)$. In contrast, what I introduce here is the evaluation of life as a whole obtained before conducting the asymmetrical comparisons.

12 Again, I do not doubt the possibility that a life is theoretically evaluated as always harmful. Recall that in Benatar's original asymmetry argument, this evaluation of harmfulness of our life is obtained in the process of deriving the harmful birth conclusion, not in the process of explaining the four asymmetries.

${ }^{13}$ Unlike Fig. 2, Spurrett $(2011,203)$ adds an additional row to Fig. 1: the left line is "Presence of a valuable human life (Good)"; the right line is "Absence of a valuable human life (Bad)." Moreover, as he suggests, the addition does not explain the asymmetry of procreational duties but has the result that there is a duty to create, in his words, "a valuable human life" (ibid.). This result seems counterintuitive. For Benatar's response to Spurrett, see Benatar 2012, 130-132.
} 


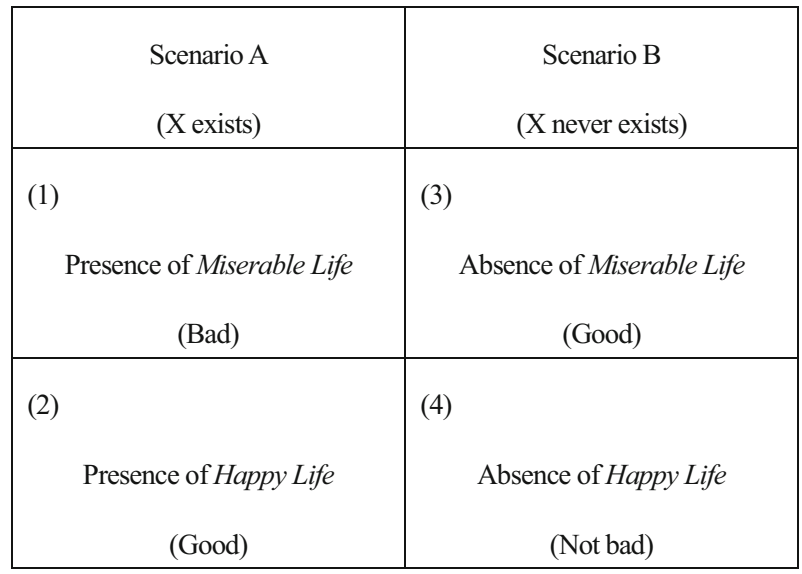

Fig. 2 Asymmetry between miserable and happy lives

miserable or happy as a whole. Note that the axiological asymmetry has not yet been applied. The results of applying it to X's life as a whole would be as follows: if X's life is miserable, it is evaluated as non-comparatively "bad" (1) and comparatively harmful (disadvantageous) relative to its absence (3); if X's life is happy, it is evaluated as non-comparatively "good" (2) and comparatively non-beneficial (non-advantageous) relative to its absence (4). ${ }^{14}$

Putting aside other moral considerations, such as parents' interests, as in Benatar's original explanation of (i), "bad" in (1) is connected to "duty to avoid"; "good" in (2) is not connected to "duty to do" because (4) is "not bad" rather than "bad." This is nothing other than the asymmetry of procreational duties.

The other three asymmetries can also be explained. A happy life as a whole is "good" in (2), but this does not provide a reason to have a child because its absence (4) is "not bad" (the first half of (ii)). The absence of a happy life as a whole is "not bad" in (4), and this does not make regret for the failure to make happy people appropriate (the second half of (iii)); it also does not make sadness for unborn happy people appropriate (the second half of (iv)). In contrast, a miserable life as a whole is "bad" in (1). This provides a reason not to create people (the second half of (ii)); it also makes regret for the sake of the people who are brought into existence appropriate (the first half of (iii)) and makes sadness for distant people who suffer appropriate (the first half of (iv)). Notably, no gap between the parts of life and life as a whole is observed in these explanations.

\footnotetext{
${ }^{14}$ The axiological asymmetry is silent on how to evaluate a life as a whole that is non-comparatively neither bad nor good. The same can be said of a part of life that is non-comparatively neither bad nor good. One may question whether Fig. 2 indicates an adequate application of Benatar's axiological asymmetry: both (1) and (2) in Fig. 1 can be states of an individual person X in Scenario A, but (1) and (2) in Fig. 2 are mutually exclusive; hence, they cannot be states of an individual person X. Therefore, Fig. 2 could simply be unintelligible. An anonymous reviewer of this paper suggests this potential doubt. The precise usage of the original Fig. 1 should be elucidated. Suppose there are two types of lives: a life with only painful parts and a life with only pleasurable parts. Fig. 1 itself indicates nothing about how many harms or benefits a particular life contains (Benatar 2006, 48). Therefore, it is applicable to the cases in which not all the quadrants are used. With regard to the supposed cases, (2) and (4) in Fig. 1 are not used for evaluating a life full of pain, and (1) and (3) are not used for evaluating a life full of pleasure. Similarly, because Fig. 2 indicates nothing about whether a particular life as a whole is miserable or happy, it is applicable to the cases in which not all the quadrants are used. This point may become clearer if Fig. 1 is read as follows (albeit only about harms): (1) and (3) indicate that if a part of life in question is harmful, that particular part of life is evaluated as bad, and its absence is good; in this instance, (2) and (4) are simply not used. Similarly, in Fig. 2, (1) and (3) indicate that if a life as a whole in question is miserable, that life is evaluated as bad, and its absence is good; in such a case, (2) and (4) are simply not used.
} 
The difference between Benatar's way of axiological evaluation and the alternative of first evaluating life as a whole lies only in the order of the evaluation steps. As described above, Benatar uses the order of "asymmetrical comparison first and as-a-whole evaluation second" to derive the harmful birth conclusion. Conversely, I use the order of "as-a-whole evaluation first and asymmetrical comparison second." Nothing special is added. As we saw in Section 3.1, where I pointed out the gap, the evaluation of life as a whole is at any rate needed somewhere in the evaluation steps by the end of the explanation. The difference is only that in my alternative, before conducting the asymmetrical comparisons, X's life is evaluated as a whole. After that, by comparing (1) with (3) and (2) with (4), while X's life is evaluated as harmful (disadvantageous over its absence) when it is bad as a whole, X's life is evaluated as non-beneficial (nonadvantageous over its absence) when it is good as a whole. This way of using the axiological asymmetry does not result in the harmful birth conclusion and the anti-natalist conclusion because it can be claimed that, while we have a duty not to create a disadvantageous life, we have no duty either to create or not to create a non-advantageous life. This is the second horn of the dilemma.

\subsection{Summarizing the Dilemma}

The dilemma arising from Benatar's asymmetry argument can be summarized as follows. Two ways are available to obtain the value as a whole to bridge the gap of the argument: the evaluation of life as a whole is made either after or before the comparison based on the axiological asymmetry. On the one hand, if it is made after, Benatar's harmful birth conclusion that coming into existence is always a harm is drawn from the axiological asymmetry because even if there are many beneficial parts in life that are not advantageous over their absence, only disadvantageous harmful parts are considered in the evaluation of life as a whole. However, the axiological asymmetry is not supported because it cannot explain our prevalent four asymmetries. On the other hand, if it is made before, the axiological asymmetry is supported because the four asymmetries are explained. However, the harmful birth conclusion is not derived. By applying the axiological asymmetry to life as a whole, both harmful and beneficial parts are considered in the non-comparative whole-life evaluation; thus, both harmful (disadvantageous) and nonbeneficial (non-advantageous) lives are evaluated in comparison to the absence of lives.

In summary, it is not the order of "as-a-whole evaluation first and asymmetrical comparison second" but of "asymmetrical comparison first and as-a-whole evaluation second" that is needed to reach the anti-natalist conclusion. However, the latter is not supported, whereas the former is.

\section{Possible Objections and Replies}

Benatar might argue that the gap is unproblematic as follows. ${ }^{15}$ The four asymmetries to be explained reflect the way in which ordinary people imprecisely think about procreation, and the axiological asymmetry is intended to be a hypothesis for the best explanation of them. (In contrast, the anti-natalist conclusion is drawn by precisely applying the axiological asymmetry to the cases of procreation.) If a hypothesis explains how people tend to think, its explanatory power might be preserved even if the explanation has a gap. However, this is not the case when there is another good explanation. As I have shown, the explanation based on Fig. 2 is at least as good as Benatar's.

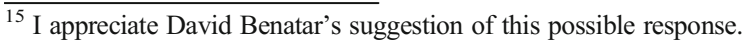


Benatar might also criticize the explanation based on the evaluation of life as a whole in the same way he criticizes an objection by Tim Bayne (2010, 50-51), who also invokes the concept of life as a whole. According to Bayne, the asymmetry of procreational duties has a better explanation than that of Benatar:

An even better explanation would appeal to an asymmetry between good and bad lives rather than to an asymmetry between good and bad experiences. The best explanation of our intuition is simply that we think it is good to avoid a miserable life but not bad to miss out on a good life. (Bayne 2010, 50)

Benatar responds that Bayne just restates the asymmetry, which is what needs to be explained. He writes:

Consider first the asymmetry of procreational duties. He says that this can be explained by appeal to the intuition that while we have a duty to avoid creating miserable lives, we have no duty to create good lives. But that is exactly what the asymmetry of procreational duties states. (Benatar 2013, 132)

Benatar's response seems slightly uncharitable. Bayne's claim can be understood as follows: what is explained is the moral asymmetry, and what explains it is the axiological asymmetry. It is not a mere restatement. This seems a rather natural way of reading Bayne's claim and is consistent with the fact that he persists in using expressions such as "an asymmetry between good and bad lives" (Bayne 2010, 52; emphasis added). ${ }^{16}$

Bayne anticipates this kind of objection to his argument from Benatar. He writes, "He might argue that we need to invoke a further, deeper asymmetry - his asymmetry - between events or states in order to explain my asymmetry (between lives)" (Bayne 2010, 52). Here, Bayne recognizes the asymmetry between lives as brute. Accordingly, he goes on to claim that (a) Benatar provides no explanation of his asymmetry, and a further explanation invoking Benatar's asymmetry adds nothing to what Bayne has already explained, and (b) that further explanation just incurs costs, such as the counterintuitive anti-natalist conclusion. However, (a) is not true if the asymmetry of life as a whole is brute, as Benatar $(2013,134)$ replies: "[A]11 explanations have to end somewhere and we have seen that even in the absence of a further explanation, mine ends deeper than does Dr. Bayne's." As I see it, Bayne need not claim that his asymmetry between lives is brute. It can be constructed from the axiological noncomparative evaluation of a whole life and Benatar's axiological asymmetry. ${ }^{17}$ Furthermore, (b) is also not true. There is a deeper explanation that does not lead to Benatar's anti-natalist conclusion, which is a cost, according to Bayne. ${ }^{18}$ It is based on Benatar's axiological

\footnotetext{
${ }^{16}$ Compare Bayne's objection with that of Thaddeus Metz $(2011,241)$, who claims that "the principle that it is permissible to start a life if and only if it would be worth continuing" explains the asymmetry of procreational duties. In response to Metz, Benatar states that this principle is "another way of stating it [the asymmetry of procreational duties]" $(2012,133)$. The difference between the two objections is that, unlike Bayne, Metz tries to explain a set of moral assessments using another moral assessment.

${ }^{17}$ When Bayne $(2010,51)$ writes about (iii) the retrospective beneficence asymmetry that "[t]he kinds of lives that we regret having brought into existence are not those of normal human beings, but those in which the goods of life are outweighed by its bads," he does make an axiological calculation of the non-comparative value of a whole life.

${ }^{18}$ It is a bad move to regard the anti-natalist conclusion as a cost. For Benatar (2006, 202-208), it is nothing other than question-begging.
} 
asymmetry. The only difference is the order of the evaluation steps, as we saw in Section 3.3 (also, recall that the axiological asymmetry itself does not provide a way of evaluating life as a whole).

As I see it, Bayne fails to fully recognize this point in invoking the evaluation of life as a whole. The very merit of invoking it is that one can endorse the structure of Benatar's axiological asymmetry to explain the four asymmetries. It is clear that the explanation using life's value as a whole is a substantial one and is not a mere restatement of the asymmetry of procreational duties, for which an explanation is required. Moreover, there is no need to add another asymmetry other than Benatar's axiological asymmetry.

\section{Order of Evaluation Steps}

Before concluding, I clarify further implications of the relation between the order of the evaluation steps and the anti-natalist conclusion more generally. Recall that there are two different orders, namely, "asymmetrical comparison first and as-a-whole evaluation second" and "as-a-whole evaluation first and asymmetrical comparison second." I deal with three types of views, and the difference in their order affects the result significantly.

\subsection{Asymmetry of Duties}

First, I show that taking the evaluation of life as a whole first has implications for a deontological view of harms and benefits. Benatar $(2006,32)$ considers another asymmetry, that "we have negative duties to avoid harm but no corresponding positive duties to bring about happiness," as an alternative explanation for our asymmetrical duties of procreation. While he rejects this explanation, as I see it, an anti-natalist conclusion can be constructed based on this general asymmetry of duties. A rough sketch of an argument would be as follows: We should carefully consider causing harms but need not consider providing benefits. For example, I will be sternly condemned if I suddenly hit a stranger, but I do not have to give my money to a stranger. While bringing a life into existence involves bringing about both harms and benefits, it is only the creation of harms that is subject to a moral duty. Thus, because all life contains harms, to avoid harms, we have a duty to create no people.

The way to avoid this result is to make an evaluation of life as a whole before connecting the axiological evaluations to the moral duties. Based on this order of evaluation, a life can be evaluated as both harmful and beneficial as a whole. Accordingly, it can be claimed that while we have a duty not to create miserable people, we have no duty to create happy people. Here, when the evaluation of life as a whole is made is critically important for our duties related to procreation.

\subsection{Asymmetry of Reasons}

Second, consider a view that insists on the asymmetry between reasons for our acts. In her critique of Benatar, Harman $(2009,781)$ claims that the asymmetry of procreational duties is explained by virtue of strong reasons against harms and much weaker reasons for benefits. This is similar to the asymmetry that invokes the concept of duty discussed in Section 5.1. Indeed, in his response to Harman, Benatar $(2013,127)$ recognizes her view as a variant of this asymmetry. Harman $(2009,781)$ writes, "In particular, we clearly have strong reasons to avoid causing people to suffer, including to avoid doing what will bring someone into existence who 
will suffer horribly. Our positive reasons to cause people to have good experiences are much weaker." It seems clear that Harman implicitly assumes here that the non-comparative evaluation of life as a whole can be used in the explanation of the asymmetry of procreational duties because the expression "suffer horribly" can be taken as "lead a horribly suffering life." However, while Harman invokes the asymmetries of reasons to reject Benatar's anti-natalism, as I see it, she opens the door to a different form of anti-natalism. This variant can be constructed as the basis of an anti-natalist conclusion if we further assume that we have no reason to bring about benefits. ${ }^{19}$ As with the asymmetry discussed in Section 5.1, a rough sketch of the argument would be as follows: Bringing a life into existence involves bringing about both harms and benefits. We have strong reasons to avoid causing people harms, but we have no reason to cause people to obtain benefits. In the case of procreation, the reasons regarding benefits never override the negative reasons against creating people. Thus, because all life contains harms, we always have a reason not to procreate. ${ }^{20}$ Here, the value of life as a whole is not assessed before connecting the axiological evaluations with the moral reasons. Again, the order of the evaluation steps plays a crucial role.

\subsection{Negative Utilitarianism}

Third, negative utilitarianism supports a different type of anti-natalism than Benatar's (Metz 2011, 236-237; Belshaw 2012, 118). Consider the hedonistic version for its simplicity. This version can be thought of as invoking an asymmetry between pain and pleasure, though in a different manner from Benatar's. Pain has moral significance, but pleasure does not. Let us call this principle the "Negative Doctrine." ${ }^{21}$ With regard to procreation, by bringing people into existence, we bring about both pains and pleasures. Increasing pleasures never contributes to making the world better, but increasing pains does contribute to making the world worse. Thus, according to the Negative Doctrine, we should not create new people. Nevertheless, by making an evaluation of life as a whole before applying the Negative Doctrine to the result of the axiological evaluations, the conclusion changes drastically. If the value of life as a whole is assessed and then the Negative Doctrine is applied to the result, it is morally obligatory to avoid bringing bad life as a whole into existence. However, bringing good life as a whole into existence is morally optional because while it does not contribute to making the world better, it does not contribute to making it worse, either. It is important that this remains the hedonistic version of utilitarianism: the values of a whole life are evaluated based on the fundamental axiology according to which pain is bad and pleasure is good. What is added is only the distinction between the evaluations of parts of life and life as a whole.

My aim is not to refine negative utilitarianism to block anti-natalism. Negative utilitarianism also implies that painless killing is required or (if not required) is at least not prohibited because almost all continuing life contains some pain (Smart 1958, 542-543), regardless of whether it accepts the whole-life evaluation. Instead, my aim is merely to suggest that changing the order of the evaluation steps produces a very different result. The anti-natalist conclusion is not derived either from Benatar's asymmetry argument or from negative

\footnotetext{
${ }^{19}$ Even without this further assumption, our procreation would be morally wrong in many more cases than generally thought. This can be taken as a weaker anti-natalist conclusion.

${ }^{20}$ The view of Seana Shiffrin (1999) has an essential commonality with this view, though she attaches significant theoretical weight to the concept of "consent" or "autonomy." Indeed, Benatar (2006, 49-54) claims that based on Shiffrin's view, a version of anti-natalism can be yielded.

21 This term is from Griffin 1979, 47.
} 
utilitarianism if the sequence of the steps taken for their evaluation is altered. However, the implications of the whole-life evaluation are different for each of these positions. The wholelife evaluation may not be attractive to a utilitarian because its imposition of an order for comparative evaluation could detract from the theoretical simplicity of utilitarianism. Moreover, such an evaluation may amount to a deviation from utilitarianism because the conception of whole-life evaluation appears to respect the separateness of persons. ${ }^{22}$ In contrast, Benatar, who is not utilitarian and elsewhere argues about the non-comparative evaluation of life as a whole (Benatar 2006, Chapter 3), has no good theoretical reason to reject the whole-life evaluation and should consider it in his asymmetry argument.

\section{Conclusion}

In this paper, I have identified a serious gap in Benatar's asymmetry argument. In bridging the gap, the asymmetry argument runs into a dilemma: the axiological asymmetry is not supported because it cannot explain the four prevalent asymmetries, or else it cannot lead to the antinatalist conclusion. This dilemma arises even if we accept all the explicit assumptions of Benatar's asymmetry argument. The only assumption that the argument presented in this paper does not share with Benatar's argument is an implicit one: the order of the evaluation steps.

The quality-of-life argument (Benatar 2006, Chapter 3) remains, and it may help to support anti-natalism. The argument focuses on how to evaluate the value of life as a whole, which is the same as the subject of this paper. Nevertheless, its thrust is different because the task of the quality-of-life argument for anti-natalism is to show that all life is non-comparatively very bad. This directly challenges our common sense. Moreover, Benatar has more recently developed a third type of argument for anti-natalism, namely the "misanthropic argument" (Benatar and Wasserman 2015, Chapter 4; see also Benatar 2006, 223-224). However, if the argument in this paper is plausible, at least one of the three pillars of Benatar's anti-natalism collapses.

Acknowledgements Earlier versions of this paper were presented at the workshop "Philosophy of Mental Time I: Human Existence in Time" held in Tokyo in 2014 and the "Seminar on Meaning in Life and Analytic Existentialism" held in Sapporo in 2018. I would like to thank the participants for their questions and comments. I would especially like to thank David Benatar, Thaddeus Metz, Ikuro Suzuki, and Tatsuya Kashiwabata for their helpful comments on the earlier versions of this paper. I am also grateful to the two anonymous reviewers who provided detailed and constructive comments that have helped me to substantially improve this paper. I would also like to thank Scribendi (www.scribendi.com) for the English language review. In addition, the reconstruction of Benatar's asymmetry argument in this paper is based on my explanatory essay entitled "Benatar no hanshussei-shugi wo dou uketomeru ka (How to Understand Benatar's Anti-Natalism)" (Gendai-Shiso 47:129-137, 2019, in Japanese). The research for this paper was supported in part by the Japan Society for the Promotion of Science (JSPS KAKENHI Grant Numbers JP18K12192, JP20H01175).

\footnotetext{
${ }^{22}$ It is well known that John Rawls (1971, 26-27) criticized (classical) utilitarianism for its disrespect of the separateness of persons. An anonymous reviewer of this paper suggests that while utilitarianism with the wholelife evaluation is still utilitarianism, it may be a step back from a hardline type. If the acceptance of the whole-life evaluation could imply the loss of an important feature of utilitarianism, such a way of evaluation generally should be considered even more seriously. The reviewer also indicates that hardline negative utilitarianism may remain an alternative position for anti-natalism. As I stated above, the pro-mortal implication seems too costly for the sole purpose of defending anti-natalism. By contrast, one of the virtues of the structure of Benatar's argument pertains to his attempt not to commit to obviously counterintuitive theses except for the middle harmful birth conclusion and the final anti-natalist conclusion.
} 
Code Availability Not applicable.

Funding Japan Society for the Promotion of Science KAKENHI, Grant Numbers JP18K12192, JP20H01175.

Data Availability Not applicable.

\section{Declarations}

Conflicts of Interest/Competing Interests Not applicable.

Open Access This article is licensed under a Creative Commons Attribution 4.0 International License, which permits use, sharing, adaptation, distribution and reproduction in any medium or format, as long as you give appropriate credit to the original author(s) and the source, provide a link to the Creative Commons licence, and indicate if changes were made. The images or other third party material in this article are included in the article's Creative Commons licence, unless indicated otherwise in a credit line to the material. If material is not included in the article's Creative Commons licence and your intended use is not permitted by statutory regulation or exceeds the permitted use, you will need to obtain permission directly from the copyright holder. To view a copy of this licence, visit http://creativecommons.org/licenses/by/4.0/.

\section{References}

Bayne T (2010) In defence of genethical parity. In: Archard D, Benatar D (eds) Procreation and parenthood: the ethics of bearing and rearing children. Clarendon Press, Oxford, pp 31-56

Belshaw C (2012) A new argument for anti-natalism. S Afr J Philos 31:117-127. https://doi.org/10.1080/ 02580136.2012 .10751772

Benatar D (2006) Better never to have been: the harm of coming into existence. Clarendon Press, Oxford

Benatar D (2012) Every conceivable harm: a further defence of anti-natalism. S Afr J Philos 31:128-164. https:// doi.org/10.1080/02580136.2012.10751773

Benatar D (2013) Still better never to have been: a reply to (more of) my critics. J Ethics 17:121-151. https://doi. org/10.1007/s10892-012-9133-7

Benatar D (2019) Not "not 'better never to have been"”: a reply to Christine Overall. Philosophia 47:353-367. https://doi.org/10.1007/s11406-018-9972-y

Benatar D, Wasserman D (2015) Debating procreation: is it wrong to reproduce? Oxford University Press, New York

Bradley B (2010) Benatar and the logic of betterness. J Ethics Soc Philos 4:1-5. https://doi.org/10.26556/jesp. $\mathrm{v} 4 \mathrm{i} 2.133$

Bradley B (2013) Asymmetries in benefiting, harming and creating. J Ethics 17:37-49. https://doi.org/10.1007/ s10892-012-9134-6

Griffin J (1979) Is unhappiness morally more important than happiness? Philos Q 29:47-55. https://oi.org/10. $2307 / 2219182$

Harman E (2009) Critical study: David Benatar. Better never to have been: the harm of coming into existence (Oxford: Oxford University Press, 2006). Noûs 43:776-785. https://doi.org/10.1111/j.1468-0068.2009. 00727.x

Metz T (2011) Are lives worth creating? Philos Pap 40:233-255. https://doi.org/10.1080/05568641.2011.591828

Overall C (2012) Why have children? The ethical debate. MIT Press, Cambridge

Rawls J (1971) A theory of justice. Harvard University Press, Cambridge

Shiffrin SV (1999) Wrongful life, procreative responsibility, and the significance of harm. Legal Theory 5:117148. https://doi.org/10.1017/S1352325299052015

Smart RN (1958) Negative utilitarianism. Mind 67:542-543. https://doi.org/10.1093/mind/LXVII.268.542

Spurrett D (2011) Hooray for babies. S Afr J Philos 30:197-206. https://doi.org/10.4314/sajpem.v30i2.67781

Publisher's Note Springer Nature remains neutral with regard to jurisdictional claims in published maps and institutional affiliations. 